\title{
Ovarian Yolk Sac Tumor: A Case Report with Review of Literature
}

\author{
${ }^{1}$ A Sreehari, ${ }^{2}$ BM Rupakala, ${ }^{3} \mathrm{C}$ Sarojamma
}

\begin{abstract}
A total of 3 to $5 \%$ of all ovarian malignancies include malignant ovarian germ cell tumors (MOGCTs). They are subdivided into germinomatous and non-germinomatous tumors. Common types of non-germinomatous tumors include yolk sac and immature teratoma. Ovarian yolk sac tumors (YST) are the second most frequent histological subtype of MOGCTs, after ovarian dysgerminoma. They account for $20 \%$ of MOGCTs and are frequent especially in childhood and in early adulthood. We report the case of a yolk sac tumor of the ovary in a 13yrs years old female.
\end{abstract}

Keywords: Alpha-fetoprotein, Ovarian germ cell tumors, Yolk sac tumor.

How to cite this article: Sreehari A, Rupakala BM, Sarojamma C. Ovarian Yolk Sac Tumor: A Case Report with Review of Literature. J Med Sci 2016;2(1):15-17.

Source of support: Nil

Conflict of interest: None

\section{INTRODUCTION}

Yolk sac tumors (YSTs) are defined as tumors that resemble the yolk sac, allantois, and extraembryonic mesenchyme and also known as endodermal sinus tumors. Yolk sac tumors are rare and a subtype of germ cell tumor. It accounts for about $10 \%$ of malignant germ cell tumors. This tumor presents as a rapidly growing mass in younger women.

\section{CASE REPORT}

A 13-year-old female came with chief complaints of lower abdominal pain and distension since 5 months. She had associated loss of weight and appetite. Per abdominal examination revealed a firm mass of about $15 \times 16 \mathrm{~cm}$ in the lower abdomen, which was mobile freely horizontally; vertical mobility was restricted.

\section{INVESTIGATIONS}

- Complete hemogram: hemoglobin 9.2 gm\%; other parameters were normal; random blood sugar, liver function test, and renal function test were normal.

\footnotetext{
${ }^{1}$ Postgraduate, ${ }^{2}$ Professor, ${ }^{3}$ Associate Professor

${ }^{1-3}$ Department of Obstetrics and Gynecology, RajaRajeswari Medical College and Hospital, Bengaluru, Karnataka, India

Corresponding Author: A Sreehari, Postgraduate, Department of Obstetrics and Gynecology, RajaRajeswari Medical College and Hospital, Bengaluru, Karnataka, India, e-mail: sreehari 9999@yahoo.co.in
}

- Serum alpha-fetoprotein (AFP) was elevated $(3,029 \mathrm{ng} / \mathrm{mL})$.

- Other tumor markers were negative.

- Follicle-stimulating hormone and luteinizing hormone were normal.

- Magnetic resonance imaging: Well-encapsulated lesion measuring $16 \times 15 \mathrm{~cm}$, uterine size appropriate for age. Impression: Dysgerminoma; karyotyping $=$ normal female karyotype; histopathology report showed features of YST (Fig. 1). Biopsy of left ovary, biopsy of right ovary, and omental biopsy were negative for malignancy; cytology was negative for malignancy.

\section{Treatment Given}

Treatment provided was left ovarian cystectomy with left salpingectomy, biopsy of right ovary with omental biopsy.

\section{Intraoperative Findings}

The patient had a right ovarian well-encapsulated tumor, measuring $15 \times 16 \mathrm{~cm}$. Uterus was infantile; left ovary and tube were normal (Figs 2 to 4 ).

\section{DISCUSSION}

Yolk sacs are defined as tumors that resemble the yolk sac, allantois, and extraembryonic mesenchyme and also known as endodermal sinus tumors.

Yolk sac tumors are commonly seen in males and females, involving the testis, ovary, and other sites, such

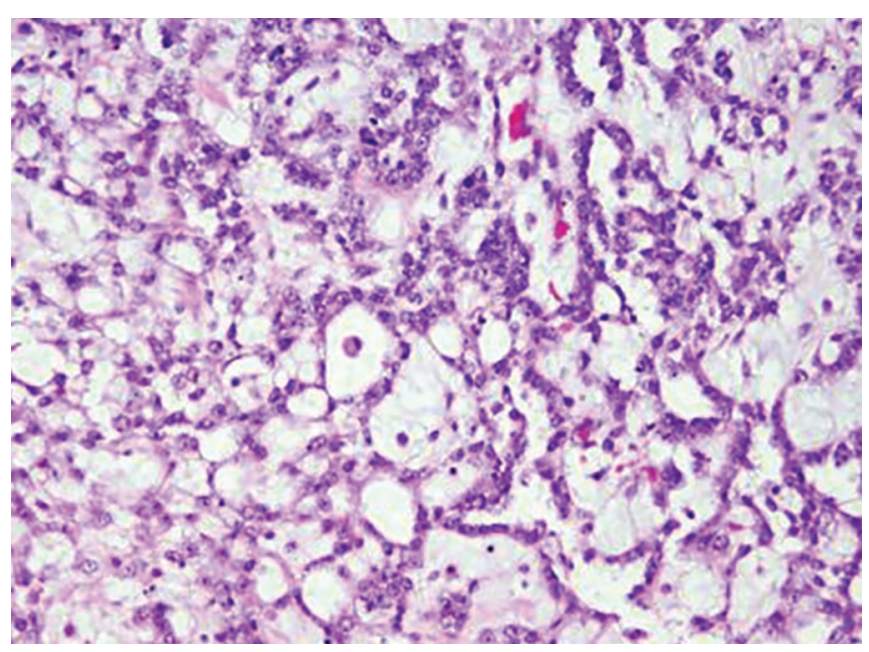

Fig. 1: Microscopic picture of YSTs. The tumor cells form a network connected by cytoplasm 


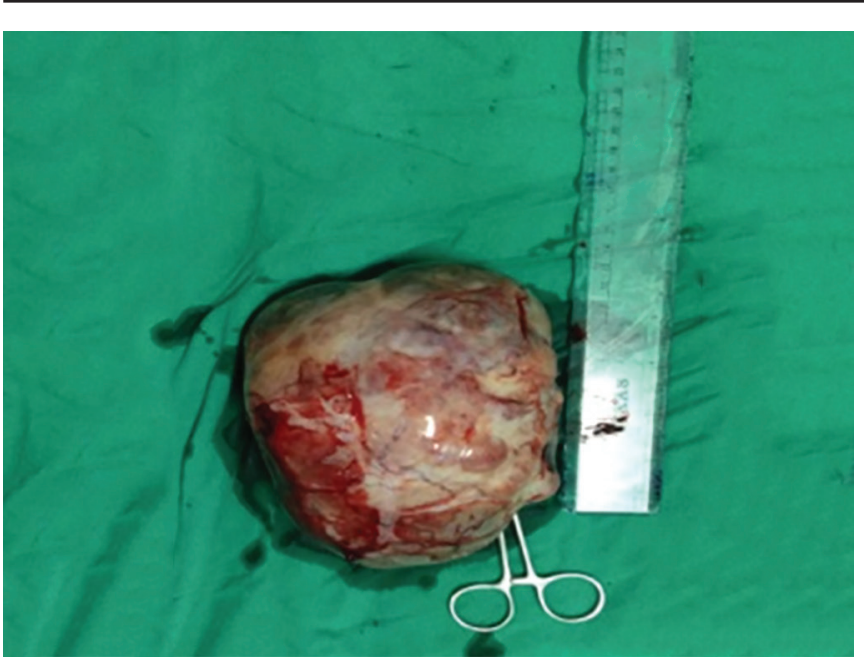

Fig. 2: The excised YST

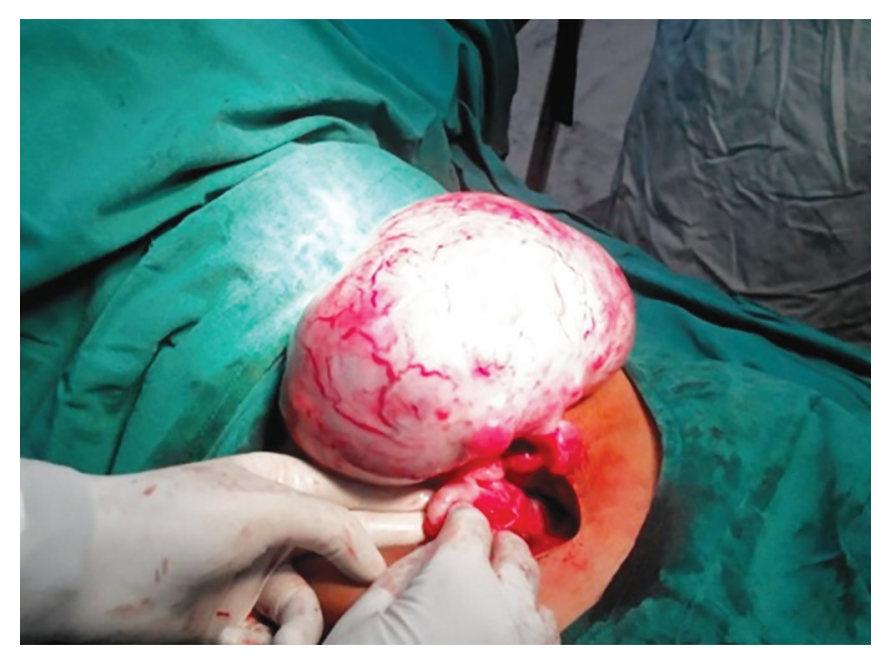

Fig. 4: The YST being dissected

as the mediastinum. Yolk sac tumors of the testis are observed in two forms, i.e., pure YST in young children and mixed type in adults. ${ }^{1,2}$

Yolk sac tumors are common in Asian children than in other races. In adults, these tumors are more common in white individuals than in other races. ${ }^{3,4}$

The etiology of YST is unknown. Hypermethylation of the RUNX3 gene promoter and overexpression of GATA-4, a transcription factor that regulates differentiation and function of yolk sac endoderm, may play important roles in the pathogenesis of YSTs. ${ }^{3,4}$ But these hypotheses have not been proved.

Yolk sac tumors are solid gray-white with a gelatinous, mucoid appearance. Necrosis, cystic changes, and hemorrhage are often seen. Grossly, the overall appearance of a YST is heterogeneous.

Many other forms of these YSTs include endodermal sinus papillary, solid, glandular, festoon, myxomatous, sarcomatoid, macrocytic, polyvesicular, hepatoid, and parietal. These various forms do not predict prognosis,

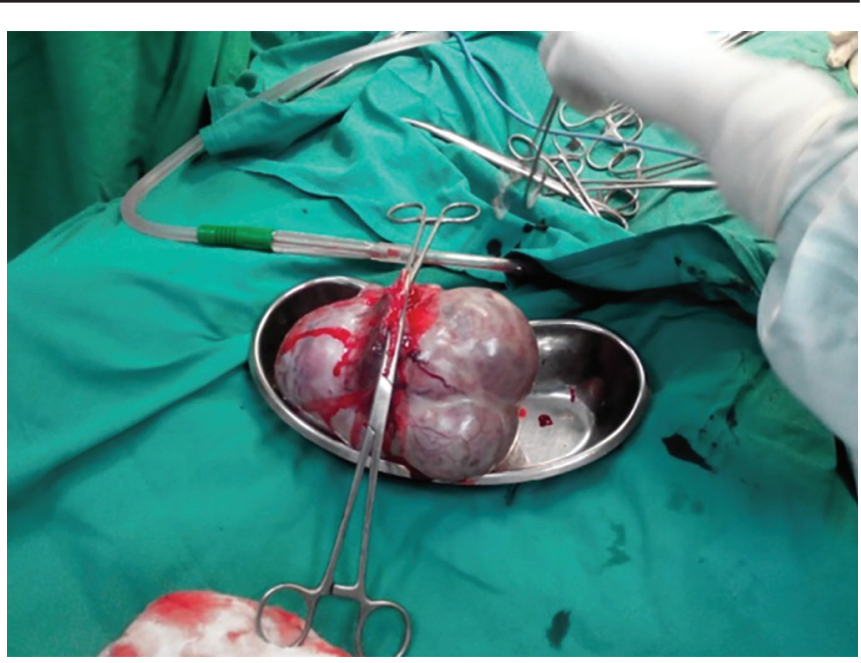

Fig. 3: The removed YST with left salpinx

but may pose difficulties in distinguishing yolk sac YSTs from other tumors or other subtypes. ${ }^{5}$

Yolk sac tumors of the endodermal sinus type consist of a central vessel rimmed by fibrous tissue, surrounded by malignant epithelial cells in a cystic space which is lined by flattened tumor cells. This endodermal sinus-like structure is called a Schiller-Duval body and is pathognomonic of YSTs. Schiller-Duval bodies are found only in 50 to $75 \%$ of tumors.

Yolk sac tumor cells express AFP, which can be detected on tissue sections by immunohistochemistry as well as by biochemical estimation. ${ }^{6}$ Alpha-fetoprotein is not specific for YSTs. ${ }^{7}$ In 40 to $80 \%$ of cases of YSTs, placental alkaline phosphatase is present, which is a marker of several different subtypes of germ cell tumors.

Other markers of YSTs have been reported recently. The prominent one is glypican 3. It is a membrane-bound heparan sulfate proteoglycan. Glypican 3 is more sensitive but less specific than AFP, as glypican 3 can be detected in some immature teratomas, in addition to liver and choreocarcinoma. ${ }^{8,9}$

The missing of short arm of chromosome 1 (1p36) and the long arm of chromosome 6 (6q) as well as presence of the long arm of chromosomes 1 and 20 has been reported in YSTs. A few papers have demonstrated the molecular signature of these tumors based on expression from microarray studies. ${ }^{10}$

About 80 to $90 \%$ YSTs in children belong to stage I. The presence of a YST component in stage I tumors has been associated with decreased likelihood of occult metastasis.

Age is not a prognostic tool and does not predict and help in diagnosing YSTs. The amount of AFP elevation, in addition to other serum tumor markers in mixed germ cell tumors, has been shown to correlate with prognosis. For serum AFP, levels $<1,000 \mathrm{ng} / \mathrm{mL}$ show a good prognosis. Levels $>10,000 \mathrm{ng} / \mathrm{mL}$ show a poor prognosis. Tumors in between these levels are associated with an 
intermediate prognosis. Staging of the YSTs is also an important prognostic factor.

\section{CONCLUSION}

Differential diagnosis of yolk sac tumor includes embryonal carcinoma, seminoma, juvenile granulosa cell tumor, and dysgerminoma. Staging of the disease and increase in AFP along with other tumor markers can help in predicting the prognosis.

\section{REFERENCES}

1. Gözdaşoğlu S, Pamir A, Çavdar AO, Ünal E, Ömer Uluoğlu, Yavuz G, Babacan E, Gökçora İH, Gü U. Summary, yolk sac tumor, a clinical and therapeutical analysis of 9 cases. Turkish J Cancer 1991;21(2):76-82.

2. The encyclopaedia of medical imaging volume IV 2, Lund, Sweden: NICER Institute/ISIS Medical Media, 2001. ISBN 82-91942-00-5.

3. Kato N, Tamura G, Fukase M, Shibuya H, Motoyama T. Hypermethylation of the RUNX3 gene promoter in testicular yolk sac tumor of infants. Am J Pathol 2003 Aug;163(2): 387-391.
4. Siltanen S, Anttonen M, Heikkila P, Narita N, Laitinen M, Ritvos O, Wilson DB, Heikinheimo M. Transcription factor GATA-4 is expressed in pediatric yolk sac tumors. Am J Pathol 1999 Dec;155(6):1823-1829.

5. Li Y, Zheng Y, Lin J, Xu G, Cai A, Chen R, Wu M. Radiologicalpathological correlation of yolk sac tumor in 20 patients. Acta Radiol 2014 Dec;57(1):98-106.

6. Young, R.H.; Scully, R.E. Testicular tumors. Chicago, IL: ASCP Press; 1990. p. 38-40.

7. Grigor KM, Detre SI, Kohn J, Neville AM. Serum alpha 1-foetoprotein levels in 153 male patients with germ cell tumours. Br J Cancer 1977 Jan;35(1):52-58.

8. Eglen DE, Ulbright TM. The differential diagnosis of yolk sac tumor and seminoma. Usefulness of cytokeratin, alphafetoprotein, and alpha-1-antitrypsin immunoperoxidase reactions. Am J Clin Pathol 1987 Sep;88(3):328-332.

9. Zynger DL, Dimov ND, Luan C, Teh BT, Yang XJ. Glypican 3: a novel marker in testicular germ cell tumors. Am J Surg Pathol 2006 Dec;30(12):1570-1575.

10. Sugimura J, Foster RS, Cummings OW, Kort EJ, Takahashi M, Lavery TT, Furge KA, Einhorn LH, Teh BT. Gene expression profiling of early- and late-relapse nonseminomatous germ cell tumor and primitive neuroectodermal tumor of the testis. Clin Cancer Res 2004 Apr;10(7):2368-2378. 